\title{
Yem Bitkisi Üreticilerinin Tarım Sigortası Yaptırma Kararlarına Etki Eden Faktörler: Balıkesir İli Örneği
}

Factors Affecting Forage Plant Producers' Decisions on Making Agricultural Insurance: The Case of Balıkesir Province

\section{Seyit HAYRAN ${ }^{1}$}

Ali BERK ${ }^{2}$

\section{Hakan İMAMOĞLU ${ }^{3}$}

${ }^{1}$ Çukurova Üniversitesi, Ziraat Fakültesi, Tarım Ekonomisi Bölümü, Adana

${ }^{2}$ Tarım ve Köyişleri Bakanlığı Tarım Reformu Genel Müdürlüğü, Ankara

${ }^{3}$ Tarım ve Köyişleri Bakanlığı İl Tarım ve

Orman Müdürlüğü, Balıkesir

*Sorumlu Yazar: shayran@cu.edu.tr

ORCID (Yazar Sırasına Göre):

(iD) 0000-0002-0223-8034

(iD) $0000-0003-3912-9656$

(iD) $0000-0002-9565-7368$

\section{Özet}

$\mathrm{Bu}$ araştırmada Balıkesir İli örneğine dayalı olarak çiftçilerin tarım sigortası yaptırma kararlarına etki eden faktörler incelenmiştir. Araştırma verileri, Balikesir İlinde basit tesadüfi örnekleme yöntemi ile belirlenen 82 çiftçiden 2018 yılında toplanmıştır. Veri analizinde ise tanımlayıcı istatistikler ve ikili lojistik regresyon analizi kullanılmıştır. Araştırma sonuçlarına göre arazi genişliği, tarımsal deneyim, bilgi ve kooperatif ortaklığı değişkenleri çiftçilerin tarım sigortası yaptırma kararlarını etkilemektedir. Buna göre, ortalama arazi genişliğinin artırılmasına yönelik önlemler, tarım sigortalarını da olumlu etkileyebilir. Ayrıca, tarım sigortalarının yaygınlaştırılması için çiftçilerin, sigorta uygulamaları konusundaki bilgilerinin artırılması ve kooperatif ortaklığının teşvik edilmesi önerilmektedir.

Anahtar Kelimeler: Tarım sigortaları, Lojistik regresyon, Yem bitkisi, Balıkesir

Gönderilme Tarihi : 19 Şubat 2020

Kabul Tarihi : 13 Mart 2020

Abstract: In this study, factors affecting farmers' decisions on making agricultural insurance based on the case of Bal1kesir Province were examined. The research 
data were collected in 2018 from 82 farmers determined by simple random sampling method in Balikesir Province. Descriptive statistics and binary logistic regression analysis were used in data analysis. According to the results of the research, the variables of land size, agricultural experience, knowledge, and cooperative partnership affected the decisions of farmers on making agricultural insurance. Accordingly, measures to increase the average land size may also affect agricultural insurance, positively. In addition, it is recommended to increase the knowledge of farmers on insurance practices and to encourage cooperative partnerships in order to extend agricultural insurance.

Keywords: Agricultural insurance, Logistic regression, Forage plant, Balıkesir

\section{GİRISS}

Türkiye ekonomisi için oldukça önemli bir sektör olan tarım, ekonominin diğer sektörlerine göre göreceli olarak daha riskli bir çalışma ortamıdır. Gelișen teknoloji, özellikle sera ve topraksız tarım uygulamaları, tarımın kontrollü koşullarda yürütülmesine yönelik önemli ilerlemeler sağlasa da, halen tarım doğal koşullara oldukça bağlıdır. Ayrıca, tarımsal girdi ve çıktıların fiyat esnekliklerinin yapısı nedeniyle, konjonktürel dalgalanmalar tarım sektörünü, diğer sektörlere göre daha hızlı ve sert bir biçimde etkilemektedir (Hardaker et al., 2004; Hoag, 2009). İklim şartları ve meteorolojik değişkenler, tarımsal hastalık etmenleri ve zararlılar, tarımda üretilen ürünün miktar, kalite, maliyet ve pazar değerini etkileyerek, tarımı daha da riskli bir ekonomik faaliyet haline getirmektedir (Ceyhan, 2003;
Ceyhan et al., 2003). Doğal koşullara, bir de ekonomik ve politik risk unsurları eklenince tarım, birçok risk faktörünün tehdidi altında kalmakta ve çiftçiler, bütün bu risk faktörlerine karşı çeşitli kültürel ve ekonomik risk yönetim stratejileri uygulamak durumunda kalmaktadırlar. Alınan teknik ve ekonomik önlemlerin yetersiz kalması halinde, uğranılan zararın tazmin edilebilmesi ve çiftçinin tarımsal üretimine devamının desteklenmesi bakımından tarım sigortaları devreye sokulmaktadır.

Tarım sigortaları, Türkiye'de 2005 yılından itibaren kurumsal olarak uygulanmaya başlanmıştır. Türkiye'de çiftçilerin risk ve risk yönetim stratejilerine yönelik algılarının analiz edildiği birçok çalışma, çiftçilerin tarım sigortalarını önemli bir risk yönetim aracı olarak gördüklerini bildirmektedir (Agır et al., 2015; Akcaoz et al., 2009; Cukur et al., 2011; Hayran, 2019; Hayran and Gül, 2015). Ancak, çiftçileri doğal risklere karşı koruyan ve bir zarar durumunda, riskin karşılanmasında çiftçiye önemli avantajlar sağlayan tarım sigortaları, devlet destekli olmasına rağmen istenilen düzeyde etkin değildir. $\mathrm{Bu}$ nedenle bu araştırmanın temel amacı Balıkesir İlinde faaliyet gösteren yem bitkisi üreticilerinin tarım sigortası yaptırma/yaptırmama nedenleri ile tarım sigortası yaptırma kararlarına etki eden faktörleri belirleyerek, tarım sigortaları uygulamalarının geliştirilebilmesi bakımından öneriler sunmaktır.

\section{MATERYAL VE YÖNTEM}

Araştırmanın ana materyalini Balıkesir İlinin 12 ilçesinde basit tesadüfi örnekleme 
(Yamane, 1967) ile belirlenen yem bitkisi üreten 82 çiftçiden anket yöntemi ile toplanan veriler oluşturmuştur. Anket çalışması 2018 yılında yapılmıştır. Verilerin analizinde ise ortalama ve standart sapma gibi tanımlayıcı istatistikler kullanılmış, sonuçlar oran ve çizelgeler halinde sunulmuştur. Ayrıca üreticilerin tarım sigortası yaptırma kararlarına etki eden faktörlerin incelenmesinde ikili lojistik regresyon analizi kullanılmıştır (Kalaycı, 2008). İkili lojistik regresyon analizinde kullanılan değișkenler, tanımları, ölçüm düzeyleri ve tanımlayıcı istatistikleri Çizelge 1'de verilmiştir.
3.ARAŞTIRMA

BULGULARI

VE

\section{TARTIŞMA}

3.1. İşletmelerde Demografik Özellikler

Anket yapılan 82 çiftçinin 80'i erkek, 2'si kadındır. Çiftçilerin medeni durumları incelendiğinde anket yapılan 82 çiftçinin \%86,58'inin evli, \%13,42'sinin ise evli olduğu görülmektedir. Çiftçilerin eğitim seviyeleri incelendiğinde, \%45,00'inin lise ve üstü seviyede eğitim gördükleri, geri kalan çiftçilerin ise ortaokul ve altı seviyede eğitim gördükleri

Çizelge 1. İkili lojistik regresyon analizinde kullanılan değişkenler

\begin{tabular}{|c|c|c|c|c|c|}
\hline Değişken & $\begin{array}{c}\text { Değişken Tanımı ve Ölçüm } \\
\text { Düzeyi }\end{array}$ & $\begin{array}{c}\text { En } \\
\text { Düşük }\end{array}$ & $\begin{array}{c}\text { En } \\
\text { Yüksek }\end{array}$ & Ortalama & $\begin{array}{c}\text { Std. } \\
\text { Sapma }\end{array}$ \\
\hline \multicolumn{6}{|c|}{ Bağımlı Değişken } \\
\hline Sigorta & $\begin{array}{l}\text { Tarım sigortası yaptırma } \\
\text { (1: evet; 0: hayır) }\end{array}$ & 0,00 & 1,00 & 0,49 & 0,50 \\
\hline \multicolumn{6}{|c|}{ Bağımsız Değişkenler } \\
\hline Yaş & Çiftçinin yaşı (y1l) & 25,00 & 68,00 & 46,33 & 9,24 \\
\hline Eğitim & $\begin{array}{l}\text { Çiftçinin en son mezun olduğu } \\
\text { okul derecesi ( } 0 \text { : ortaokul ve altı } \\
\text { seviyede eğitim; } 1 \text { : lise ve üstü } \\
\text { seviyede eğitim) }\end{array}$ & 0,00 & 1,00 & 0,45 & 0,50 \\
\hline Deneyim & $\begin{array}{l}\text { Çiftçinin yem bitkileri yetiştirme } \\
\text { deneyimi (y1) }\end{array}$ & 2,00 & 45,00 & 16,34 & 6,30 \\
\hline Arazi & $\begin{array}{l}\text { Çiftçinin toplam yem bitkisi } \\
\text { yetiştirdiği alan }(\mathrm{da})\end{array}$ & 5,00 & 300,00 & 72,68 & 63,43 \\
\hline Mülkiyet & $\begin{array}{l}\text { 1: çiftçinin üretim yaptığ } \text { arazinin } \\
\text { tamamı mülk arazi ise; } 0 \text { : diğer }\end{array}$ & 0,00 & 1,00 & 0,77 & 0,42 \\
\hline Uzmanlaşma & $\begin{array}{l}\text { 1: çiftçi sadece yem bitkisi } \\
\text { üretiyorsa; } 0: \text { diğer }\end{array}$ & 0,00 & 1,00 & 0,22 & 0,42 \\
\hline Kooperatif & $\begin{array}{l}\text { 1: çiftçi yem bitkileri konusunda } \\
\text { faaliyet gösteren bir kooperatife } \\
\text { ortak ise; } 0 \text { : diğer }\end{array}$ & 0,00 & 1,00 & 0,70 & 0,46 \\
\hline Bilgi & $\begin{array}{l}\text { 1: çiftçinin tarım sigortası } \\
\text { yaptırmadan önce, tarım } \\
\text { sigortaları konusunda bilgisi var } \\
\text { ise; 0: diğer }\end{array}$ & 0,00 & 1,00 & 0,78 & 0,42 \\
\hline
\end{tabular}


belirlenmiştir. Çiftçilerin yaş ortalamaları 46,33 yıl, yem bitkisi yetiştirme deneyimleri ise ortalama 16,34 yıldır. Ankete katılan çiftçiler, ortalama 72,68 da alandan üretim yapmaktadırlar. Çiftçilerin \%77,00'si sadece mülk arazisinde üretim yaparken, geri kalan çiftçiler kiracılık ve ortakçılık ile de arazi işlemektedirler. Anket uygulanan çiftçilerin \%22,00'si sadece yem bitkisi üretmekte, geri kalan çiftçiler ise yem bitkisinin yanında diğer bitkisel üretim faaliyetlerinde de bulunmaktadırlar. Çiftçilerin tarım danışmanı ile çalışma oranları oldukça düşüktür. Anket uygulanan çiftçilerin yalnızca \%6,00'sı tarım danışmanı ile çalıştıklarını ifade etmişlerdir. Buna karşılık çiftçilerin örgütlenme seviyeleri ise yüksek bulunmuştur. Ankete katılan çiftçilerin \%70,00'i yem bitkileri konusunda faaliyet gösteren bir kooperatife ortaktırlar (Çizelge 2).

\section{2.Çiftçilerin Tarım Sigortası Yaptırma Durumları}

Araştırmada yem bitkisi üreticilerinin sigorta yaptırma kararları ile tarım sigortası yaptırma ve yaptırmama nedenleri incelenmiştir. Çiftçilerin $\% 78,05$ 'i tarım sigortaları konusunda daha önceden bilgi sahibi olduklarını ifade etmişlerdir. Üreticilerin \%71,95'i ise 2005 y1lından itibaren tarım sigortalarında devlet desteği uygulandığını bilmektedir. Üreticilerin \%76,83'ü de devlet destekli tarım sigortası sisteminde, sigorta priminin \%50,00'sinin devlet destekli olduğunu bilmektedir. Yem bitkisi üreten çiftçilerin tarım sigortası yaptırma durumları incelendiğinde, ankete katılan çiftçilerin \%48,78'inin en az bir kez tarım sigortası yaptırdıkları görülmüştür. $\mathrm{Bu}$ 40 çiftçinin ise \%57,50'si 0 - 4 y1ldır, \%27,50'si 5 - 10 yıldır ve \%15,00'i 11 - 15 yıldır tarım

Çizelge 2. İncelenen İşletmelerde Demografik Özellikler

\begin{tabular}{|c|c|c|c|}
\hline \multicolumn{2}{|c|}{ Özellikler } & Kişi & $\%$ \\
\hline \multirow{3}{*}{ Cinsiyet } & Kadın & 80 & 97,56 \\
\hline & Erkek & 2 & 2,44 \\
\hline & Toplam & 82 & 100,00 \\
\hline \multirow{3}{*}{ Medeni Durum } & Evli & 71 & 86,59 \\
\hline & Bekar & 11 & 13,41 \\
\hline & Toplam & 82 & 100,00 \\
\hline \multirow{3}{*}{ Eğitim } & Ortaokul ve altı & 45 & 54,88 \\
\hline & Lise ve üstü & 37 & 45,12 \\
\hline & Toplam & 82 & 100,00 \\
\hline \multirow{3}{*}{ Arazi Mülkiyeti } & $\begin{array}{l}\text { Sadece mülk arazisinde üretim } \\
\text { yapan çiftçi sayısı }\end{array}$ & 63 & 76,83 \\
\hline & $\begin{array}{l}\text { Kiracılık ve ortakçılık ile de } \\
\text { üretim yapan çiftçi sayısı }\end{array}$ & 19 & 23,17 \\
\hline & Toplam & 82 & 100,00 \\
\hline
\end{tabular}


sigortası yaptırmaktadırlar.

Çiftçilerin tarım sigortası yaptırma nedenleri incelendiğinde, en önemli nedenin tarımsal kredi kullanımı için bir zorunluluk olmasının olduğu görülmektedir. Çiftçilerin geçmişte yaşadıkları ürün-hayvan kayıpları da önemli nedenlerden arasındadır. Benzer şekilde diğer çiftçilerin uğradıkları zararlarda çiftçilerin tarım sigortası yaptırma kararları almalarında etkili bir unsurdur (Çizelge 3).

Çizelge 3. Üreticilerin tarım sigortası yaptırma nedenleri

\begin{tabular}{|l|r|r|}
\hline \multicolumn{1}{|c|}{ Nedenler } & \multicolumn{1}{c|}{ Kişi } & \multicolumn{1}{c|}{$\%$} \\
\hline Tarım kredisi kullanımı nedeniyle & 19 & 54,29 \\
\hline Geçmişte yaşanan ürün-hayvan kayıpları & 12 & 34,29 \\
\hline Diğer çiftçilerin uğradıkları zararlar & 4 & 11,43 \\
\hline Sigorta elemanlarının önerileri & 0 & 0,00 \\
\hline Tarım sigortası yaptıranların memnuniyeti & 0 & 0,00 \\
\hline Toplam & 35 & 100,00 \\
\hline
\end{tabular}

Çiftçilerin tarım sigortası yaptırmama nedenleri de araştırma kapsamında incelenmiştir. Buna göre çiftçilerin tarım sigortası yaptırmamalarının en önemli nedeni, tarım sigortaları için ödenen primi gereksiz bir masraf unsuru olarak görmeleridir. Çiftçilerin bir kısmı, bir doğal afet (sel, dolu, taşkın gibi) yaşanması durumunda, tarım sigortası yaptırmayan çiftçilerin uğradıkları zararların zaten devlet tarafından karşılandığını, sigorta yaptıran çiftçilerin ise uğradıkları zararı, sigorta şirketlerinden tazmin edebilmek için uzun bir süre beklediklerini ifade etmektedirler. Yaşanan bu gibi durumlar da, zamanla tarım sigortası için ödenen prim tutarlarının, çiftçiler tarafından gereksiz görülmesi eğilimine neden olmaktadır. Bir kısım çiftçiler ise tarım sigortas1 primlerini gereksiz görmemekle birlikte, bu primi ödeyecek maddi imkanları olmadığı için tarım sigortası yaptırmadiklarını belirtmişlerdir. Bazı çiftçiler de daha önce hiç hasar veya zarara uğramadıkları için sigorta yaptırmadiklarını ifade etmişlerdir. Çiftçilerin hasar ödemelerinin zamanında ve hızlı bir şekilde tahsil edilemeyeceğine ilişkin algıları da tarım sigortas1 yaptırmama nedenleri arasındadır.

Çizelge 4. Üreticilerin tarım sigortası yaptırmama nedenleri

\begin{tabular}{|l|r|r|}
\hline \multicolumn{1}{|c|}{ Neden } & \multicolumn{1}{c|}{ Kişi } & \multicolumn{1}{c|}{ \% } \\
\hline Gereksiz bir maliyet olarak görüyorum & 13 & 30,23 \\
\hline Sigorta primlerini yüksek buluyorum & 8 & 18,60 \\
\hline Örf adetlerimize uygun görmüyorum & 6 & 13,95 \\
\hline Daha önce hiç hasar ya da zarar yaşamadım & 6 & 13,95 \\
\hline $\begin{array}{l}\text { Hasar ödemelerinin zamanında ve hızlı bir şekilde yapılmayacağı } \\
\text { endişesini taşıorum }\end{array}$ & 5 & 11,63 \\
\hline Arazim az, sigortaya ihtiyaç yok diye düşünüyorum & 3 & 6,98 \\
\hline Kanuni bir zorunluluk yok & 1 & 2,33 \\
\hline Sigorta yaptırma alışkanlığım yok & 1 & 2,33 \\
\hline Toplam & 43 & 100,00 \\
\hline
\end{tabular}


Ayrıca, bazı çiftçiler işledikleri arazi miktarının az olmasından dolayı tarım sigortasına ihtiyaç duymadıklarını belirtmişlerdir. $\mathrm{Bu}$ araştırma bulgusu, arazi toplulaştırma çalışmalarının tarım sigortaları sisteminin yaygınlaştırılması için de önemli olduğunu göstermektedir. Bir kısım çiftçi de yasal zorunluluk olmaması veya sigorta yaptırma alışkanlığı olmamasını sigorta yaptırmama nedenleri arasında belirtmişlerdir (Çizelge 4).

\section{3.Çiftçilerin Tarım Sigortası Yaptırma Kararına Etki Eden Faktörler}

Çiftçilerin sigorta yaptırma kararlarına etki eden faktörlerin incelenmesi amacıyla, çiftçilerin hayatlarında en az bir kez tarım sigortası yaptırıp yaptırmama durumlarının bağımlı değişken olarak alındığı ikili lojistik regresyon modeli kullanılmıştır. Çözümlenen modele ilişkin sonuçlara göre ki-kare değeri 45,573 olarak saptanmış ve elde edilen lojistik regresyon modelinin istatistiki olarak anlamlı olduğu belirlenmiştir $(p<0.000)$. Modelin Loglikehood değeri 68,055, Cox\&Snell $\mathrm{R}^{2}$ değerinin 0.426 ve Nagelkerke $\mathrm{R}^{2}$ değerinin ise 0.569 olarak hesaplanmıştır.

Lojistik regresyon modeli sonuçlarına göre başta sabit terim olmak üzere kooperatif, bilgi, arazi ve deneyim değișkenleri anlamlı bulunmuștur. Yaş, uzmanlaşma, eğitim ve mülkiyet değişkenleri ise anlamlı değildir (Çizelge 5).

Çiftçilerin yaşları ile sigorta yaptırma kararları arasında ilişki bildiren bazı çalışmalar mevcuttur. Ünal, (2017) Adana İlinde yaptığı çalışmasında çiftçilerin tarım sigortası yaptırma kararları ile yaşları arasında pozitif ve anlamlı bir ilişki bildirmiştir. Benzer bir diğer çalışmada İkikat Tümer, (2011) benzer bir sonuç bildirmiştir. Ancak mevcut çalışmada yem bitkisi üreticilerinin tarım sigortası yaptırma kararları ile yaşları arasında ki ilişkiye dair katsayı pozitif bulunmakla birlikte, istatistiksel olarak anlamlı değildir. Çiftçilerin eğitim seviyeleri ile sigorta yaptırma kararları arasında pozitif ve anlamlı bir ilişki beklenmektedir. Ancak, mevcut çalışmada

Çizelge 5. Üreticilerin tarım sigortası yaptırma kararlarına etki eden faktörler

\begin{tabular}{|c|c|c|c|c|c|c|c|c|}
\hline \multirow[t]{2}{*}{ Değişkenler } & \multirow[t]{2}{*}{ B } & \multirow[t]{2}{*}{ S.E. } & \multirow[t]{2}{*}{ Wald } & \multirow[t]{2}{*}{ df } & \multirow[t]{2}{*}{ Sig. } & \multirow[t]{2}{*}{$\operatorname{Exp}(B)$} & \multicolumn{2}{|c|}{ 95\% C.I.for EXP(B) } \\
\hline & & & & & & & Lower & Upper \\
\hline Yaş & 0,016 & 0,037 & 0,184 & 1 & 0,668 & 1,016 & 0,945 & 1,092 \\
\hline Uzmanlaşma & $-0,585$ & 0,815 & 0,516 & 1 & 0,473 & 0,557 & 0,113 & 2,750 \\
\hline Kooperatif & 1,433 & 0,685 & 4,375 & 1 & 0,036 & 4,191 & 1,094 & 16,047 \\
\hline Bilgi & 3,513 & 1,153 & 9,278 & 1 & 0,002 & 33,541 & 3,499 & 321,523 \\
\hline Eğitim & 0,365 & 0,652 & 0,313 & 1 & 0,576 & 1,440 & 0,402 & 5,164 \\
\hline Arazi & 0,010 & 0,005 & 3,508 & 1 & 0,061 & 1,010 & 1,000 & 1,021 \\
\hline Deneyim & 0,228 & 0,075 & 9,215 & 1 & 0,002 & 1,256 & 1,084 & 1,455 \\
\hline Mülkiyet & $-0,432$ & 0,788 & 0,301 & 1 & 0,583 & 0,649 & 0,139 & 3,041 \\
\hline Sabit & $-8,942$ & 2,532 & 12,474 & 1 & 0,000 & 0,000 & & \\
\hline
\end{tabular}


çiftçilerin eğitimleri ile sigorta yaptırma kararları arasında ki ilişkinin katsayısı pozitif ancak istatistiksel olarak anlamsızdır. İkikat Tümer (2011), Tokat İlinde yaptığı çalışmasında çiftçilerin tarım sigortası yaptırma kararları ile eğitim seviyeleri arasında pozitif ve anlamlı bir ilişki bildirmiştir. Mevcut araştırmada çiftçilerin yem bitkisi yetiştiriciliği deneyimleri ile tarım sigortası yaptırma kararları arasında pozitif ve anlamlı bir ilişki tespit edilmiştir. $\mathrm{Bu}$ araştırma bulgusu Ünal (2017) ve İkikat Tümer (2011) ile uyumludur. Mevcut araştırmada çiftçilerin tarım sigortası yaptırmadan önce, tarım sigortaları konusunda bilgi sahibi olmaları ile tarım sigortaları yaptırma kararları arasında pozitif ve anlamlı bir ilişki tespit edilmiştir. $\mathrm{Bu}$ araştırma bulgusu, Ünal (2017) tarafından desteklenmektedir. Bir diğer önemli araştırma bulgusu da yem bitkilerialanında faaliyet gösteren bir tarımsal kooperatife ortak olan çiftçilerin tarım sigortası yaptırma olasılıklarının, ortak olmayan çiftçilere göre daha fazla olduğudur. Ünal (2017) araştırmasında kooperatif ortaklığ1 ile tarım sigortası yaptırma eğilimi arasında pozitif ve anlamlı bir ilişki bildirmiştir. Benzer şekilde İkikat Tümer (2011) çiftçilerin üretici birliğine üye olmalarının bitkisel ürün sigortası yaptırma isteği üzerine etkisinin pozitif ancak istatistiksel olarak anlamsız olduğunu bildirmiştir. Bir diğer önemli araştırma bulgusu da çiftçilerin işledikleri arazi genişliği arttıkça, tarım sigortası yaptırma olasılıkları da artmaktadır. $\mathrm{Bu}$ araştırma bulgusu, sera üretimi yapan çiftçilerin, işledikleri sera genişliği ile sigorta yaptırma olasılıkları arasında pozitif ve anlamlı bir ilişki bildiren Sherrick et al. (2004) ile uyumludur.

\section{SONUÇ}

$\mathrm{Bu}$ araştırmada, Balıkesir ilinde yem bitkileri üreticilerinin sigorta yaptırma durumları, sigorta yaptırma ve yaptırmama nedenleri ile tarım sigortası yaptırma kararlarına etki eden faktörler incelenmiştir. Araştırma sonuçlarına göre üreticilerin en önemli sigorta yaptırma nedenileri kredi kullanımı olarak tespit edilirken, üreticilerin en önemli sigorta yaptırmama nedenleri ise sigortay 1 gereksiz bir maliyet unsuru olarak görmeleridir. Üreticilerin sigorta yaptırma kararlarına etki eden faktörler ise çiftçinin işlediği arazi genişliği, tarımsal deneyim, kooperatif ortaklığı ve sigorta yaptırmadan önce tarım sigortaları konusunda bilgi sahibi olup olmaması olarak belirlenmiştir. Araştırma sonuçlarından yola çıkarak tarım sigortalarının yaygınlaştırılması bakımından, arazi toplulaştırma başta olmak üzere uygun politikalarla ortalama arazi genişliklerinin artırılmasına yönelik çalışmalar yapılması, çiftçilerin kooperatif ortaklığı şeklinde örgütlenmesinin teşvik edilmesi önerilebilir. Ayrıca, araştırma sonuçları çiftçilerin daha önceden tarım sigortaları konusunda bilgi sahibi olmaları halinde, tarım sigortası yaptırma olasılıklarının arttığını göstermiştir. Tabiidir ki bir konuda bilgi sahibi olmak, o konuda çiftçilerin uygulama yapmalarını kolaylaştırmaktadır. Tarım sigortaları konusunda da, sigortacılık uygulamalarını bilen, sağladığı faydaları ve özellikle ekonomik sürdürülebilirlik açısından sigortacının önemini kavramış bir çiftçinin bundan yararlanmak istemesi de doğaldır. $\mathrm{Bu}$ bakımdan, gerek kamu kuruluşları gerekse de TARSIM üreticilerin bilgilendirilmelerine yönelik yayım faaliyetlerinde bulunmalıdır. 


\section{KAYNAKLAR}

Agır, H. B., Saner, G., and Adanacioglu, H. (2015). Risk sources encountered by farmers in the open field production of strawberry and risk management strategies: a case of Menemen - Emiralen District of Izmir. Journal of Agricultural Sciences 21, 13 - 25.

Akcaoz, H., Kizilay, H., and Ozcatalbas, O. (2009). Risk management strategies in dairy farming: A case study in Turkey. Journal of Animal and Veterinary Advances, 8(5):949-958.

Ceyhan, V. (2003). “Tarım işletmelerinde risk analizi: Çorum İli Kızılırmak Havzası örneği," Ondokuz Mayıs Üniversitesi, Ziraat Fakültesi, Samsun, Araştırma Seri (6).

Ceyhan, V., Bozoğlu, M., and Cinemre, H. (2003). Measuring yield and price risks for dairy farms and designing risk management strategies: the case of Tonya, Turkey. Bodenkultur, 215 - 220.

Cukur, F., Saner, G., Cukur, T., and Dayan, V. (2011). Risks and risk strategies on olive farming in Milas district of Mugla province, Turkey. Journal of Food, Agriculture \& Environment, 190 - 194.

Hardaker, J., Huirne, R., Anderson, J., and Lien, G. (2004). "Coping with risk in agriculture," CABI: 1. Edition.

Hayran, S. (2019). Perceptions of wheat producers towards risk and risk management strategies: A case study from Turkey. Ciência Rural 49, 1 - 10.
Hayran, S., and Gül, A. (2015). Risk perception and management strategies in dairy farming: a case of Adana Province of Turkey. Turkish Journal of Agriculture - Food Science and Technology 3, 952 961.

Hoag, D. (2009). "Applied risk management in agriculture," United States: CRC Press; 1 Edition.

İkikat Tumer, E. (2011). Bitkisel Ürün Sigortas1 Yaptırma İsteğinin Belirlenmesi: Tokat İli Örneği. Atatürk Üniversitesi Ziraat Fakültesi Dergisi 42, 153-157.

Kalayc1, Ş. (2008). "SPSS Uygulamalı Çok Değişkenli İstatistik Teknikleri," Asil Yayın Dağıtım, İstanbul.

Sherrick, B. J., Barry, P. J., Ellinger, P. N., and Schnitkey, G. D. (2004). Factors Influencing Farmers' Crop Insurance Decisions. American Journal of Agricultural Economics 86, 103-114.

Ünal, H. (2017). Çiftçilerin tarım sigortası yaptırma kararlarına etki eden faktörler: Adana İli örneği. Çukurova Üniversitesi Fen Bilimleri Enstitüsü Tarım Ekonomisi Anabilim Dalı (Basılmamış Yüksek Lisans Tezi), Adana.

Yamane, T. (1967). "Elemantary Sampling Theory," Hall Inc. Englewood Cliffs, Nt. 